Article

\title{
Experimental Investigation of the Thermofluid Characteristics of Shell-and-Plate Heat Exchangers
}

\author{
Howard Lee, Ali Sadeghianjahromi $\mathbb{D}$, Po-Lun Kuo and Chi-Chuan Wang * \\ Department of Mechanical Engineering, National Chiao Tung University, 1001 University Road, Hsinchu 300, \\ Taiwan; howardlee7108@gmail.com (H.L.); asadeghi1363@gmail.com (A.S.); sunny224358@gmail.com (P.-L.K.) \\ * Correspondence: ccwang@mail.nctu.edu.tw; Tel.: +886-3-5712121 (ext. 55105)
}

Received: 10 September 2020; Accepted: 7 October 2020; Published: 12 October 2020

check for updates

\begin{abstract}
An experimental study regarding the thermofluid characteristics of a shell-and-plate heat exchanger with different chevron angles $\left(45^{\circ} / 45^{\circ}, 45^{\circ} / 65^{\circ}\right.$, and $\left.65^{\circ} / 65^{\circ}\right)$ with a plate diameter of $440 \mathrm{~mm}$ was carried out. Water was used as the working fluid on both sides and the corresponding temperatures ranged from $30-70{ }^{\circ} \mathrm{C}$. The flow rate on the plate or shell side ranged from $10-60 \mathrm{~m}^{3} / \mathrm{h}$. The effects of chevron angles on the heat transfer and fluid flow characteristics of shell-and-plate heat exchangers were studied in detail. With regard to the heat transfer performance on the plate side, a higher chevron angle $\left(65^{\circ} / 65^{\circ}\right)$ resulted in a significantly better performance than a low chevron angle $\left(45^{\circ} / 45^{\circ}\right)$. The effect of the chevron angle became even more pronounced at high Reynolds numbers. Unlike the plate side, an increase in the chevron angle had a negative effect on the heat transfer performance of the shell side. Additionally, this opposite effect was more prominent at low Reynolds numbers due to the comparatively large contribution of the manifold. The friction factor increased appreciably with the increase in the chevron angle. However, when changing the chevron angle from $45^{\circ} / 45^{\circ}$ to $65^{\circ} / 65^{\circ}$, the increase in the friction factor was about 3-4 times on the plate side while it was about 2 times on the shell side. This can be attributed to the presence of the distribution/collection manifold on the shell side. Empirical correlations for the Nusselt number and friction factor were developed for different combinations of chevron angles with mean deviations of less than $1 \%$.
\end{abstract}

Keywords: shell-and-plate heat exchanger; chevron angle; heat transfer; Nusselt number; friction factor; correlations

\section{Introduction}

Shell-and-tube heat exchangers are the most common heat exchangers and are widely used in several industries as well as having process and petrochemical applications. Although shell-and-tube heat exchangers (STHE) are versatile and reliable and they can withstand high pressure and temperature, they have some disadvantages. For example, the thermal efficiency is relatively low $(40-60 \%)$ in comparison with plate heat exchangers ( $>90 \%)$. Additionally, periodic alterations in the shell flow stream as a result of the baffle plates can cause a large drop in pressure. Also, if a flow recirculation zone exists in the shell side, this can appreciably weaken the shell-side performance. Furthermore, there are several leakage and bypass issues on the shell side. Another disadvantage of this type of heat exchanger is the vibration induced by the fluid flow due to fluid instability, vortex shedding, multi-phase buffeting, etc. [1]. Many of the aforementioned problems (e.g., flow re-circulation, high pressure drop, leakages and bypasses, low thermal efficiency, and vibration) can be addressed through the use of a plate heat exchanger (PHE), which offers high heat transfer performance, less volume, lower weight, and is easy to clean (for the gasket type). However, they can withstand lower pressure and temperature and leakages may still occur in gasket type PHEs. 
In order to tackle the disadvantages of STHE and PHE, a combination of these two types of heat exchangers, a "shell-and-plate heat exchanger (SPHE)" was developed. This new type of heat exchangers has many advantages such as a higher heat transfer coefficient (HTC), more compactness, lighter weight, easier maintenance, and easier cleaning. Also, since the plates are welded and there is no gasket in this type of heat exchanger, it can withstand higher pressure and temperature without any leakage. These heat exchangers are a suitable candidate for different applications such as in chemical processes, refrigeration industries as evaporators and condensers, power stations, etc. Despite their superiority, there are only a few experimental and numerical studies on SPHEs. Uehara et al. [2] developed a new type of SPHE for ocean thermal energy conversion (OTEC) plants with different plate types such as the porous surface, fluted, and impinging plate type for the evaporator and two different plate types for the condenser. They used titanium and the working fluids were ammonia and R-22. The experimental results showed that the porous plate had superior heat transfer performance compared to the other plate types. Nakaoka and Uehara [3] investigated the performance of an evaporator which was used experimentally in OTEC plants. The type of evaporator was SPHE and ammonia and R-22 were considered as the working fluids. Correlations for obtaining the heat transfer performance of the water side were developed for both working fluids. Uehara et al. [4] performed experimental investigations on a SPHE type evaporator for OTEC plants with 30 aluminum powder-coated plates. The results showed that the plate size has a negligible effect on the boiling HTC, while it declined with an increase in superheat temperatures. Park et al. [5] performed an experimental study on the condensation of R-410A in a vertical oblong SPHE with a corrugated trapezoid $45^{\circ}$ chevron angle. The results showed that an increase in vapor quality or mass flux will increase condensation $\mathrm{HTC}$ and $\triangle \mathrm{P}$. Moreover, an increase in the saturation temperature will decrease the condensation $\mathrm{h}$ with a negligible effect on $\Delta \mathrm{P}$. Empirical correlations were also presented for $\mathrm{Nu}$ and $\mathrm{f}$. The same experiments were also performed for the evaporation with the same geometry and working fluid $[6,7]$. The results were the same as the experiment for condensation. In another experiment, the researchers changed the working fluid to R-134a with the same results [8]. A horizontal SPHE, which was used for a feedwater heater was tested by Taylor et al. [9]. The heat transfer performance was obtained and compared with empirical correlations. The results showed good agreement with the correlations and proved that SPHEs are a suitable alternative to shell-and-tube heat exchangers since they offer superior performance and compactness. Arsenyeva et al. [10] presented developments in the design of SPHEs used in the preheat train of a crude oil distillation unit. They performed optimizations on the number of plates with different corrugated geometries. The results revealed that the SPHE lessens the formation of fouling on surfaces and it can also bear more wall shear stresses resulting from the different flow rates of the hot and cold sides. The heat transfer performance of the condensation of R-245fa in a SPHE used in high-temperature heat pumps was reported by Lim et al. [11]. They claimed that an increase in the mass flux and vapor quality and a decline in the saturation temperature enhances the condensation $\mathrm{h}$ and $\Delta \mathrm{P}$. Furthermore, the condensation HTC and two-phase $\Delta \mathrm{P}$ in a SPHE are $5.9 \%$ and $16.7 \%$ less than the brazed PHE with the same heat transfer area, respectively. They also developed some correlations based on their experimental results. Albrecht and Ho [12] developed a numerical model to simulate the heat transfer performance of $\mathrm{SCO} 2$ in a SPHE with a moving packed-bed that was used in solar power plants. The fatigue analysis of a titanium alloy SPHE under high pressure (2 MPa) was executed numerically by Li et al. [13]. The life cycle, deterioration, and safety factor were also obtained from the fatigue analysis. Abbas et al. [14] performed a detailed numerical simulation analysis on the heat transfer performance of a single-phase SPHE with chevron angles of $45^{\circ}$ and $75^{\circ}$. Their results indicated that the friction factor $\mathrm{f}$ is larger in the shell and inner channel for a chevron angle of $75^{\circ}$, while this parameter in the inner channel is lower than that of the chevron angle of $45^{\circ}$. The overall performance of the shell channel with a chevron angle of $45^{\circ}$ is better at a lower Reynolds number. Moreover, the optimum corrugation aspect ratio of 0.75 and 0.53 was obtained for the inner channel and shell channel, respectively. Jo et al. [15] compared the heat transfer performance of an evaporator SPHE and PHE with R-1234ze (E) as the working fluid. These experimental results suggest 
that mass flux has a significant effect on the evaporation HTC in both types of evaporators, while the influence of saturation temperature is negligible. An increase in vapor quality reduces the evaporation HTC in a PHE, while its influence in a SPHE is also insignificant. The two-phase $\Delta \mathrm{P}$ is highly affected by the saturation temperature and mass flux in both types of evaporators. Correlations for $\mathrm{Nu}$ and $\mathrm{f}$ were also developed. Song et al. [16] performed an experimental study on the evaporation heat transfer performance of a SPHE in high-temperature R-245fa heat pumps. Results showed improved evaporation HTC and increased two-phase $\triangle \mathrm{P}$ with the increase in mass flux and vapor quality. Moreover, the heat transfer characteristics of a SPHE with an upward flow direction outperform the downward flow direction. The correlations developed for $\mathrm{Nu}$ and two-phase $\mathrm{f}$ were also presented. A detailed investigation of the fluid flow characteristics of an SPHE with corrugated sinusoidal pattern was carried out experimentally by Wang et al. [17] and the corresponding flow patterns in the upward and downward flow were proposed.

Despite the outstanding features of SPHE, studies on the thermofluid performance of this type of heat exchangers are still very rare. Also, most of the research is associated with two-phase flow including evaporation or condensation. Although the most effective geometrical parameter for the thermofluid characteristics of SPHEs is the chevron angle, very few studies have examined this parameter in detail. Although numerical simulations can be used for the design and optimization of heat exchangers and can easily show detailed flow behavior, they also need validation from experimental data. Also, numerical errors due to discretization of governing equations, simplifying assumptions, geometry simplification, turbulence modeling, etc., may occur. To ensure the suitability of simulations, test data is first required before further optimizations and simulations can be carried out. The objective of this study was to experimentally investigate the heat transfer and flow friction performance of this type of heat exchanger with different combinations of chevron angles on both the shell and plate side. The effects of different parameters such as the chevron angle of the shell side and plate side on the heat transfer and flow friction characteristics of SPHE are studied in detail. Empirical correlations for the heat transfer and flow friction characteristics of shell-and-plate heat exchangers were developed based on different chevron angles, which have not been reported in prior studies.

\section{Experiments}

\subsection{Experimental Setup and Procedure}

The schematic of the experimental setup is illustrated in Figure 1. The working fluid is water for both the hot and cold sides. For the hot side, water is heated in a PHE by hot water that comes from the boiler and is subsequently pumped into the SPHE. PHE is used for the accurate control of the hot side water. Water for the cold side is cooled by a cooling tower and pumped to the SPHE in the test section. The SPHE is insulated in order to prevent heat loss as shown in Figure 2b. A sample of the plates inside the SPHE is presented in Figure 2c. The cross section of the plates has a wavy configuration (Figure 2d). The geometrical parameters of the SPHE are tabulated in Table 1. The plates are circular and consist of two different chevron angles. Hot water enters the shell side from the top nozzle with an inlet temperature of $70^{\circ} \mathrm{C}$ and is distributed in the shell side plates, while cold water enters the plate side from the bottom nozzle with an inlet temperature of $30^{\circ} \mathrm{C}$ and is distributed in the plate side plates (Figure 2a). The hot and cold streams flow counter-currently. Resistance temperature detectors (RTD) were used to obtain highly accurate temperature measurements at the inlets and outlets and these RTDs were pre-calibrated with $0.1^{\circ} \mathrm{C}$ precision. The pressure drops were measured by Yokogawa differential pressure transducers with $\pm 0.35 \%$ accuracy. The remote type with model numbers of AXF050G, AXFA14G, AXF100G, and AXFA14G were used for the shell side, while models AXF150G and AXF250G of the integral type were used for the plate side. The inlet and outlet pressure were measured using WIKA A-10 pressure transducers with $\pm 0.5 \%$ accuracy. Yokogawa flowmeters were also applied to measure the flow rates on both the hot (model EJA118E with an accuracy of $\pm 0.2 \%$ ) and cold (model EJA110A with accuracy of $\pm 0.065 \%$ ) side. 


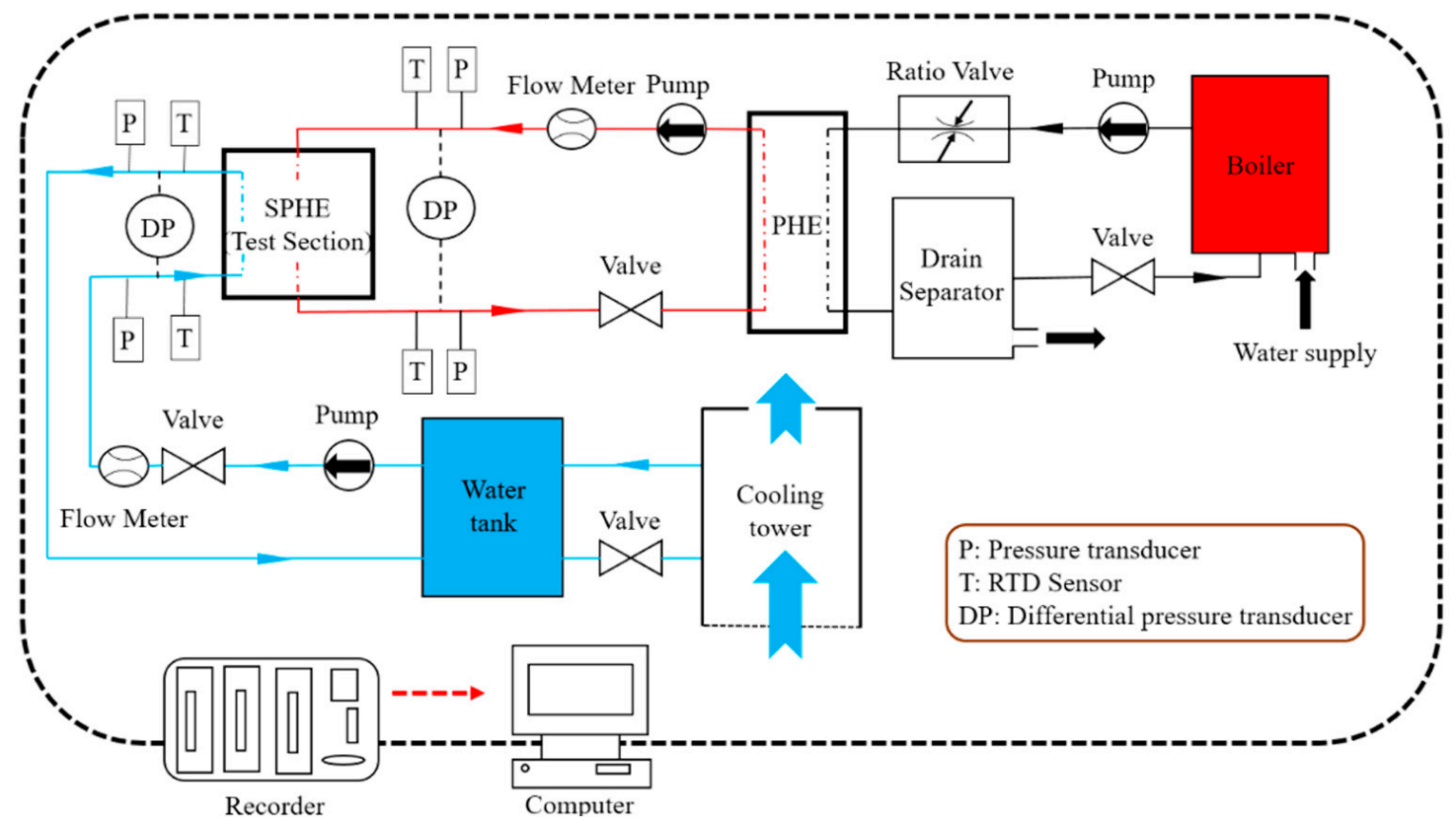

Figure 1. Schematic of the experiment setup.

Table 1. Geometrical parameters of the sample plate of the shell-and-plate heat exchanger (SPHE).

\begin{tabular}{lc}
\hline \multicolumn{1}{c}{ Geometrical Parameter } & Value \\
\hline Plate outside diameter $(D)(\mathrm{mm})$ & 440 \\
inlet \& outlet nozzle diameters (plate side) $\left(d_{p}\right)(\mathrm{mm})$ & 80 \\
inlet \& outlet nozzle diameters (shell side) $\left(d_{s}\right)(\mathrm{mm})$ & 80 \\
Distance between inlet \& outlet nozzles (plate side) $\left(l_{p}\right)(\mathrm{mm})$ & 290 \\
Distance between inlet \& outlet nozzles (shell side) $\left(l_{s}\right)(\mathrm{mm})$ & 440 \\
Number of plates $(N)$ & 32 \\
Plate thickness $(t)(\mathrm{mm})$ & 1 \\
Chevron angle $(\beta)\left({ }^{\circ}\right)$ & $45 \& 65$ \\
Wavy length $\left(l_{w}\right)(\mathrm{mm})$ & 7.5 \\
Wavy height $\left(h_{w}\right)(\mathrm{mm})$ & 2.2 \\
Enlargement ratio $(\varphi)$ & 1.196 \\
\hline
\end{tabular}

Experiments were carried out for three different cases: chevron angles of $45^{\circ}$, chevron angles of $65^{\circ}$, and a combination of chevron angles of $45^{\circ}$ and $65^{\circ}$ (Table 2). For each case, the volumetric flow rate of shell side changed, while the volumetric flow rate of the plate side was maintained as constant and comparatively large to ensure the dominant resistance on the plate side. Then a follow-up Wilson plot method was employed to derive the relationship on plate side. Analogously, the relationship of the shell-side can be obtained by fixing a very large flow rate at the plate side, followed by using the Wilson plot technique to obtain the heat transfer relation of the shell-side. Further details of the Wilson plot technique are given below. 


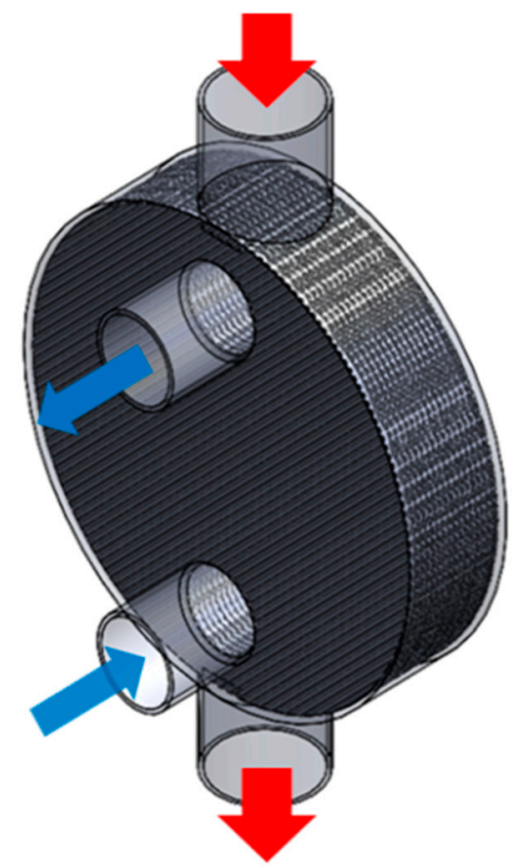

(a)

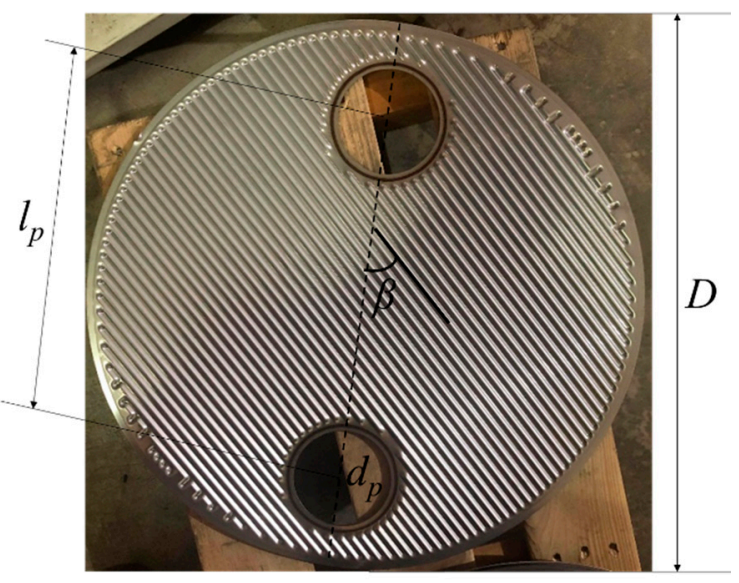

(c)

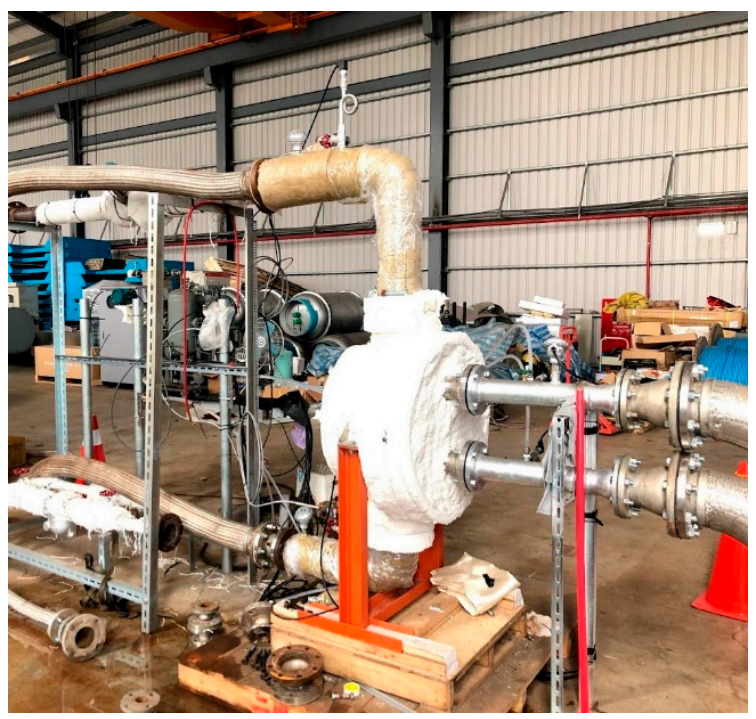

(b)
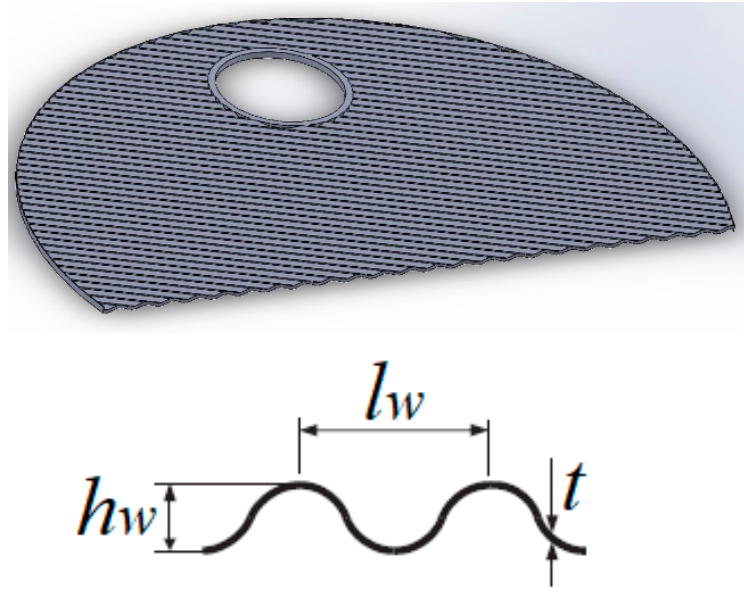

(d)

Figure 2. (a) Cold and hot water flow paths, (b) SPHE (test section) in the experiment setup, (c) a sample of plates, (d) the wavy configuration of the plate cross section.

Table 2. Volumetric flow rates in different experimental cases.

\begin{tabular}{ccc}
\hline \multirow{2}{*}{ Cases } & \multicolumn{2}{c}{ Volumetric Flow Rates $\left(\mathbf{m}^{\mathbf{3}} / \mathbf{h}\right)$} \\
\cline { 2 - 3 } & Plate Side & Shell Side \\
\hline \multirow{2}{*}{$45^{\circ} / 45^{\circ}$} & $12 \sim 59$ & 54 \\
& 60 & $10 \sim 60$ \\
$45^{\circ} / 65^{\circ}$ & $11 \sim 40$ & 37 \\
& 37 & $10 \sim 37$ \\
$65^{\circ} / 65^{\circ}$ & $10 \sim 35$ & 34 \\
& 36 & $10 \sim 34$ \\
\hline
\end{tabular}




\subsection{Data Reduction}

The Reynolds number $(R e)$ is the ratio of the inertial force to the viscous force and can be obtained as follows:

$$
\operatorname{Re}=\frac{\rho V D_{h}}{\mu}
$$

where $D_{h}$ is the hydraulic diameter, which is calculated from the following formula [16]:

$$
D_{h}=\frac{2 h_{w}}{\varphi}
$$

The heat transfer rate $(\dot{Q})$ is calculated from the following correlation:

$$
\dot{Q}=\dot{m} c_{p} \Delta T=U A \Delta T_{l m}
$$

where $\Delta T$ is the temperature difference between the inlet and outlet and $\Delta T_{l m}$ is the logarithmic mean temperature difference, which can be obtained from the following correlation:

$$
\Delta T_{l m}=\frac{\left(T_{\text {out }, s}-T_{\text {in }, p}\right)-\left(T_{\text {in }, s}-T_{\text {out }, p}\right)}{\ln \left(\frac{T_{\text {out }, s}-T_{\text {in }, p}}{T_{\text {in }, s}-T_{\text {out }, p}}\right)}
$$

$U A$ can be also determined as follows:

$$
\frac{1}{U A}=\frac{1}{h_{s} A}+\frac{t}{k_{p} A}+\frac{1}{h_{p} A}
$$

The Nusselt number $(\mathrm{N} u)$ can be obtained by using the Wilson plot $[18,19]$ based on the following correlation:

$$
N u=\frac{h D_{h}}{k}=C_{0} \operatorname{Re}^{C_{1}} \operatorname{Pr}^{C_{2}}
$$

where $C_{2}$ can be considered constant as $1 / 3$ [16] and $\operatorname{Pr}$ is the Prandtl number, which can be obtained from the following formula:

$$
\operatorname{Pr}=\frac{c_{p} \mu}{k}
$$

The flow rate is varied on a specific side (e.g., plate side) while the thermal resistance of the other side is kept comparatively small and constant. By combining Equations (3) to (7) and using linear fitting data with $R^{2}>0.999, C_{0}$ and $C_{1}$ can be calculated by trial and error (since there are two unknown parameters in one equation [3]) and consequently, the Nusselt number for the shell and plate sides can be specified.

In order to determine the friction factor $(f)$, the frictional pressure drop was specified. The measured total pressure drop $(\Delta P)$ in the SPHE consists of frictional $\left(\Delta P_{f}\right)$, elevation $\left(\Delta P_{g}\right)$, acceleration $\left(\Delta P_{a}\right)$, and port $\left(\Delta P_{\text {port }}\right)$ pressure drops [15]. By specifying the frictional pressure drop $\left(\Delta P_{f}\right)$ from the measured total pressure drop, the friction factor $(f)$ can be determined from the following correlation:

$$
f=\frac{D_{h} \Delta P_{f}}{2 l \rho V^{2}}
$$

Note that the velocity is obtained at the centerline of the plate or shell side. In order to obtain the friction factor for the plate side or shell side, $l$ is substituted by $l_{p}$ or $l_{s}$ in the above correlation, respectively, with the relative frictional pressure drop. $V$ is the mean channel flow velocity, which is obtained in the maximum cross-sectional area of the plate [14]. 


\subsection{Uncertainty Analysis}

Uncertainty analysis was performed using the methods presented in $[16,20]$. The summary of the uncertainties of the measured parameters and the calculated parameters are tabulated in Table 3. Based on Table 3, the different uncertainties that exist in the measurements result in up to $10.2 \%$ and $10.19 \%$ error in the calculation of heat transfer coefficient and fiction factor, respectively. A sample of the procedure for the uncertainty calculation is included in the Appendix A.

Table 3. Uncertainties for the measured and calculated parameters.

\begin{tabular}{lc}
\hline \multicolumn{1}{c}{ Parameter } & Uncertainty $\mathbf{( \% )}$ \\
\hline Flow rate & 0.35 \\
Pressure drop & 0.27 \\
Temperature & 0.1 \\
Heat transfer rate & 1.39 \\
Log-mean temperature difference & 0.37 \\
Overall heat transfer coefficient & 1.41 (for $R e=5500)$ \\
& $2.4($ for $R e=1300)$ \\
Heat transfer coefficient (shell side) & 3.7 (for $R e=9030)$ \\
& $10.2($ for $R e=1400)$ \\
Heat transfer coefficient (plate side) & $5.3($ for $R e=5500)$ \\
Friction factor & 9.5 (for $R e=1300)$ \\
\hline
\end{tabular}

\section{Results and Discussions}

As mentioned above, three cases with different combinations of chevron angles were investigated: $45^{\circ} / 45^{\circ}, 45^{\circ} / 65^{\circ}$, and $65^{\circ} / 65^{\circ}$. The heat transfer and fluid flow characteristics of the SPHE in different cases are discussed in detail.

\subsection{Heat Transfer Characteristics of SPHE}

The Nusselt number was calculated by combining Equations (3) to (7). The Wilson plot for all cases mentioned in Table 2 is illustrated in Figure 3. From the linear fitting data $(y=a x+b)$, constants $C_{0}$ and $C_{1}$ can be obtained so that $\mathrm{a}=C_{0}^{-1}$ and $\mathrm{x}=\operatorname{Re} e^{(-C 1)}$. The calculated $C_{0}$ and $C_{1}$ for all cases are tabulated in Table 4.

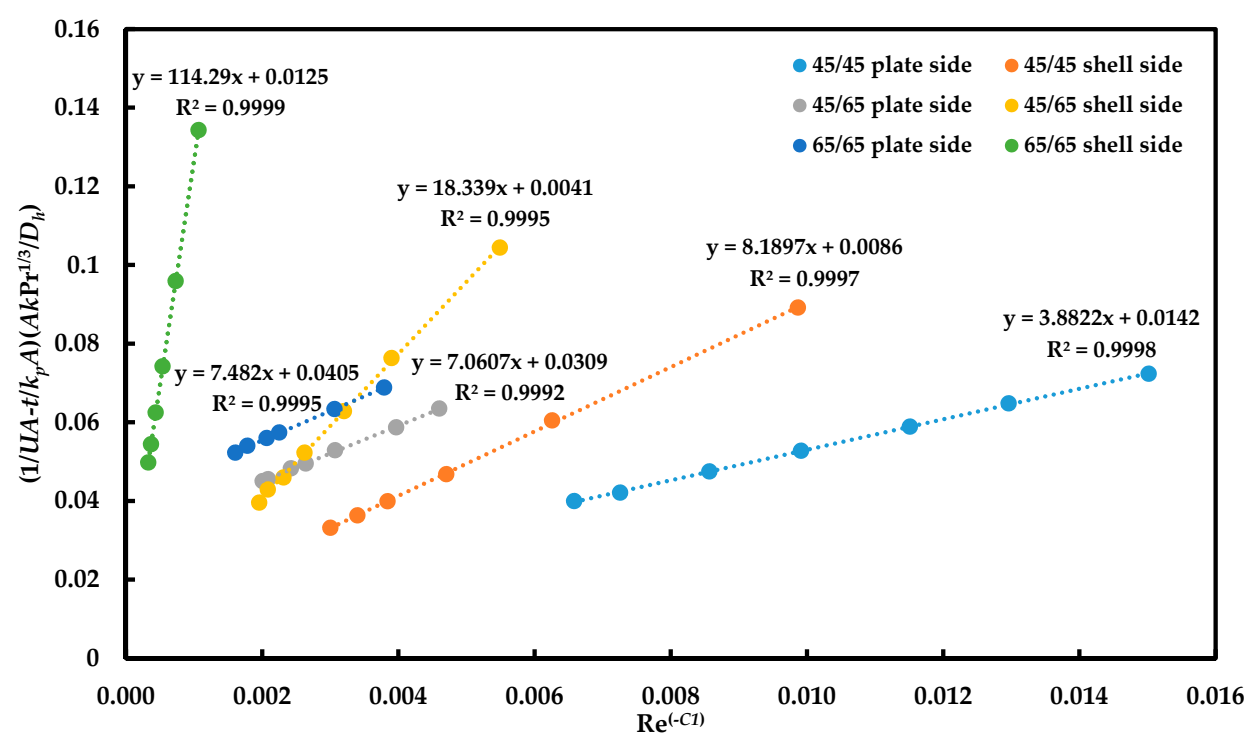

Figure 3. Wilson plot for all experimental cases. 
Table 4. Values of $C_{0}$ and $C_{1}$ for all cases.

\begin{tabular}{cccccc}
\hline \multirow{2}{*}{ Cases } & \multicolumn{2}{c}{ Volumetric Flow Rates $\left(\mathbf{m}^{\mathbf{3}} \mathbf{h}\right)$} & \multirow{2}{*}{$\boldsymbol{C}_{\mathbf{0}}$} & \multirow{2}{*}{$\boldsymbol{C}_{\mathbf{1}}$} \\
\cline { 2 - 3 } & Plate Side & Shell Side & & \\
\hline \multirow{2}{*}{$45^{\circ} / 45^{\circ}$} & $12 \sim 59$ & 54 & 0.2576 & 0.5829 \\
& 60 & $10 \sim 60$ & 0.1221 & 0.6375 \\
$45^{\circ} / 65^{\circ}$ & $11 \sim 40$ & 37 & 0.1416 & 0.7543 \\
& 37 & $10 \sim 37$ & 0.0545 & 0.7206 \\
$65^{\circ} / 65^{\circ}$ & $10 \sim 35$ & 34 & 0.1336 & 0.7920 \\
& 36 & $10 \sim 34$ & 0.0087 & 0.9383 \\
\hline
\end{tabular}

By obtaining the $C_{0}$ and $C_{1}$ through the Wilson plot technique, the Nusselt number and HTC can be calculated for all cases. Figure 4 shows the Nusselt number vs. the Reynolds number subject to different chevron angles on both the plate and shell sides. It can be seen that the Nusselt number increases with the rise in the Reynolds number for different chevron angles due to the higher heat transfer rate in higher flow rates. Furthermore, the Nu number increases remarkably with the chevron angle on the plate side as depicted in Figure 4a. Additionally, the increase becomes even more pronounced as the Reynolds number increases. For instance, at a Reynolds number of 3000, the $\mathrm{Nu}$ of the $65^{\circ} / 65^{\circ}$ plate is about three times higher than that of the $45^{\circ} / 45^{\circ}$ plate. This is illustrated in the schematic in Figure 5a,b. The increase in the chevron angle results in more turbulent mixing, which yields higher heat transfer performance like a typical plate heat exchanger [21], and also offers better flow distribution alongside the plate. Note that there is a basic difference between the round plate of the shell-and-plate heat exchanger and the convention rectangular plate in the plate heat exchanger. For a lower chevron angle combination like the $45^{\circ} / 45^{\circ}$ plate shown in Figure $5 \mathrm{a}$, the flow rate around the edge of the round plate is lower than in the center region due to its longer flow path. For a larger chevron angle such as the $65^{\circ} / 65^{\circ}$ combination, the flow rate is effectively forced to circulate across the edge as depicted in Figure 5b, thereby resulting in a better flow distribution. In summary, on the plate side, higher turbulent mixing and better flow distribution contribute to a significant increase in the heat transfer performance of the $65^{\circ} / 65^{\circ}$ plate. However, the effect of chevron angle on the heat transfer performance on the shell side does not follow the plate side. In fact, the increase in chevron angle slightly offsets the heat transfer performance when the chevron angle is increased from $45^{\circ} / 45^{\circ}$ to $65^{\circ} / 65^{\circ}$ as shown in Figure $4 \mathrm{~b}$. The deterioration is more prominent at a lower Reynolds number. Note that there is fundamental difference in the flow field between the plate side and the shell side. The flow on the shell side encounters the distribution/collection manifold, which causes the flow to spread, resulting in some secondary flow behind the distribution/collection manifold as schematically illustrated in Figure 5c,d. Apparently, the resultant secondary flow jeopardizes the heat transfer and increases the pressure drop. Although the increase in the chevron angle can create better mixing, it also increases the ineffective area behind the distribution/collection manifold, thus lowering the heat transfer performance significantly at the lower Reynolds numbers. Although better turbulent mixing at a higher Reynolds number can ease the negative effect of the chevron angle, the heat transfer performance of $45^{\circ} / 45^{\circ}$ is still about $10 \%$ higher than that of $65^{\circ} / 65^{\circ}$ at a Reynolds number of 6000 . 


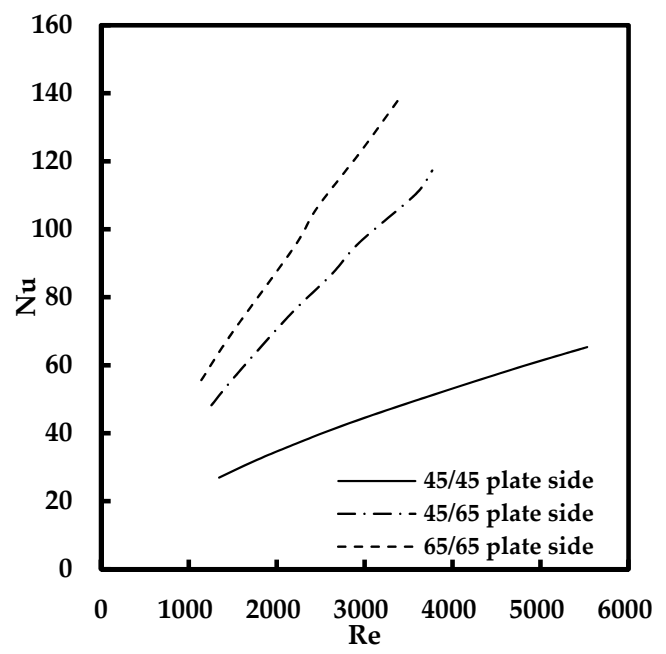

(a)

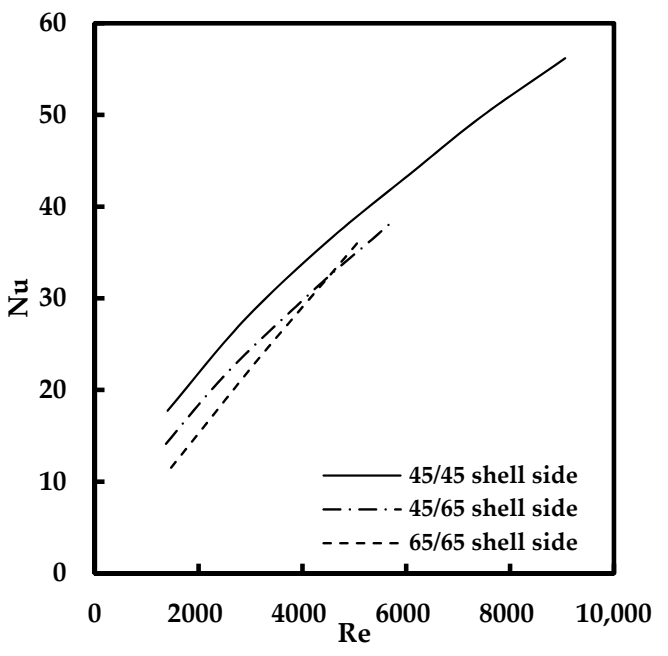

(b)

Figure 4. (a) Nusselt number vs. Reynolds number for different flow rates in (a) the plate side and (b) the shell side.
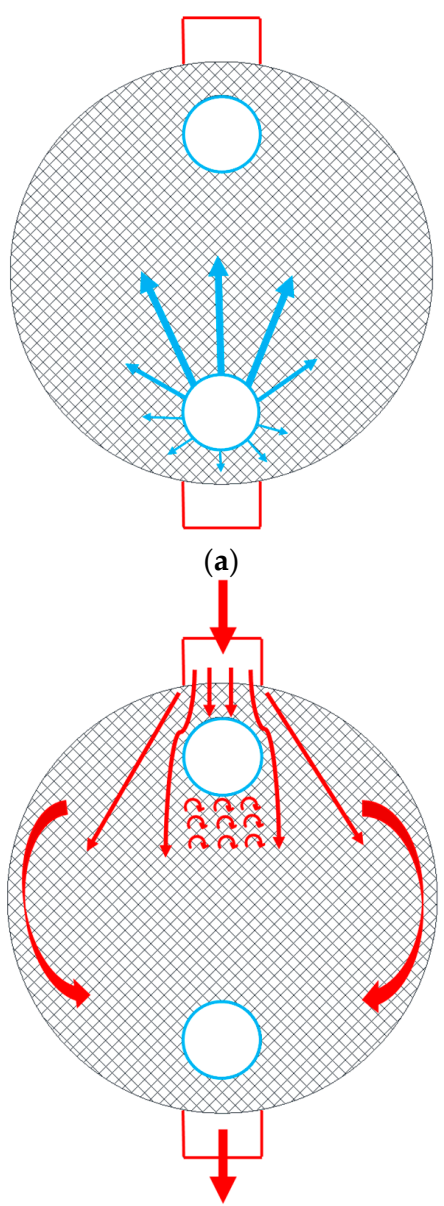

(c)
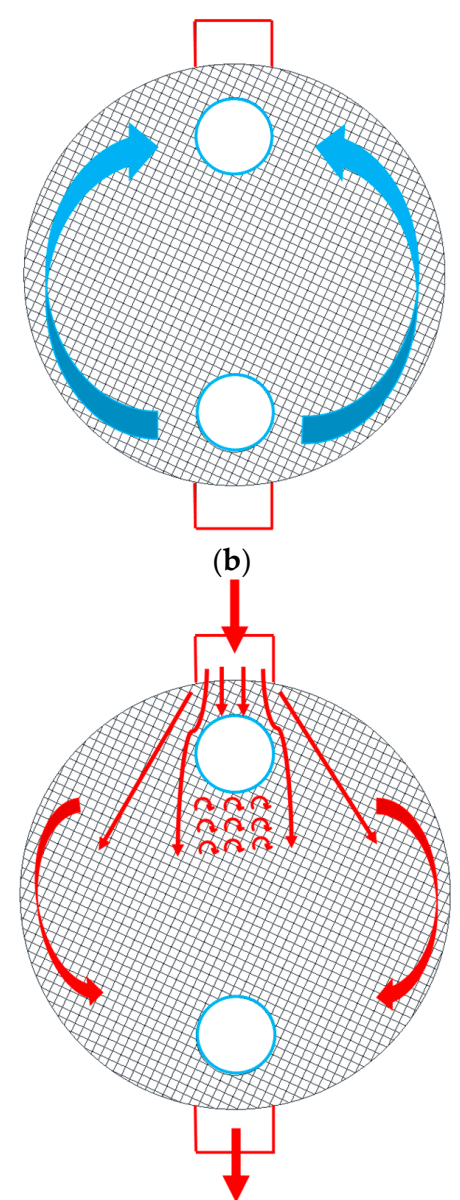

(d)

Figure 5. Flow distribution through the plates for $(\mathbf{a})$ the plate side $\left(\beta=45^{\circ}\right),(\mathbf{b})$ the plate side $\left(\beta=65^{\circ}\right)$, (c) the shell side $\left(\beta=45^{\circ}\right)$, and (d) the shell side $\left(\beta=65^{\circ}\right)$. 


\subsection{Flow Friction Characteristics of the SPHE}

In order to perform a precise investigation of the flow friction characteristics of the SPHE, the pressure drop was measured in isothermal conditions, meaning that the inlet temperatures for both the cold and hot side were the same and there was no heat transfer between the plate and shell sides. The friction factor was plotted with various Reynolds numbers for all cases and these are shown in Figure 6. Based on the results, the friction factor decreases with an increase in the Reynolds number for all cases. The increase in the flow rate increases the frictional pressure drop. However, the increase in velocity is much higher than the increase in the frictional pressure drop and consequently, the friction factor declines slightly. In both cases, where the plate side flow rates are varied (Figure 6a) and the shell side flow rates are varied (Figure 6b), the increase in the chevron angle results in a considerable increase in the friction factor. Note that there is a difference in the increase rate of the friction factor between the plate side and shell side when the chevron angle is changed from $45^{\circ} / 45^{\circ}$ to $65^{\circ} / 65^{\circ}$. On the plate side, there is a difference of about 3-4 times. However, there is a difference of about 2 times on the shell side. Again, this can be attributed to the presence of the distribution/collection manifold on the shell side. The main flow is forced to flow across the manifold, therefore lessening the effect of the pressure drop caused by the plate geometry (the chevron angle).

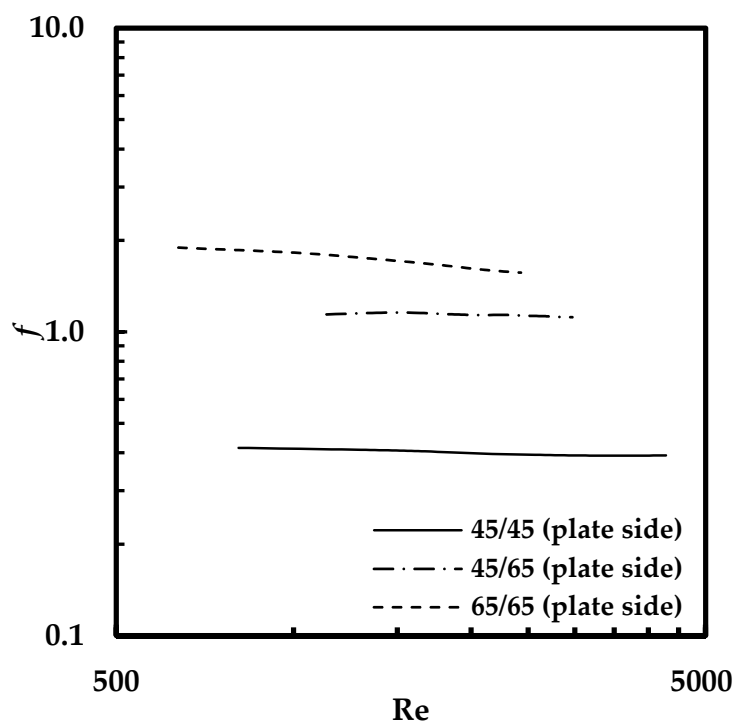

(a) Different flow rates on the plate side

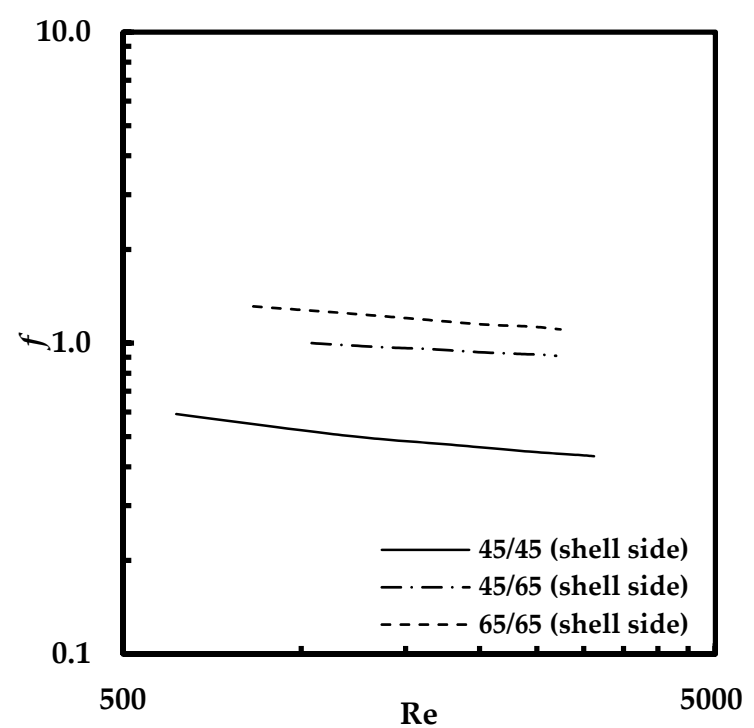

(b) Different flow rates on the shell side

Figure 6. Friction factor vs. Reynolds number for all experimental cases.

\subsection{Development of Empirical Correlations}

Up until now, there are no predictive correlations for the single-phase performance of the shell-and-plate heat exchanger. Therefore, empirical correlations for the Nusselt number and friction factor for shell and plate sides were developed based on the present experimental data. The correlations are functions of the Reynolds number, the Prandtl number, and the chevron angle. Since each plate consists of two different chevron angles on each side $\left(\beta_{1}\right.$ and $\left.\beta_{2}\right)$, the average chevron angle $(\alpha)$ in radian is used in the developed correlations, which is defined as follows:

$$
\alpha=\frac{\beta_{1}+\beta_{2}}{2}
$$

The Nusselt number for both the shell and plate sides can be obtained from the following correlation:

$$
N u=C_{0} e^{C_{1}} \operatorname{Pr}^{1 / 3}
$$


where the parameters $C_{0}$ and $C_{1}$ are functions of the chevron angle and can be predicted from the following correlations for the shell and plate sides, respectively, which have been developed by data curve fitting and trial and error.

Shell side:

$$
\begin{gathered}
C_{0}=5.8972\left(\frac{\sin \alpha}{\alpha}\right)^{2}-8.9026\left(\frac{\sin \alpha}{\alpha}\right)+3.3571 \\
C_{1}=2.2093 \alpha^{2}+3.3799 \alpha-1.9292
\end{gathered}
$$

Plate side:

$$
\begin{gathered}
C_{0}=22.899\left(\frac{\sin \alpha}{\alpha}\right)^{2}-37.688\left(\frac{\sin \alpha}{\alpha}\right)+15.627 \\
C_{1}=-2.1946 \alpha^{2}+4.8123 \alpha-1.8429
\end{gathered}
$$

The comparison between the Nusselt numbers obtained from the experimental data and the developed correlations are illustrated in Figure 7. The correlations are able to predict all the experimental data within $\pm 5 \%$. The mean deviations for the predicted Nusselt numbers for the shell and plate sides are less than $0.5 \%$.

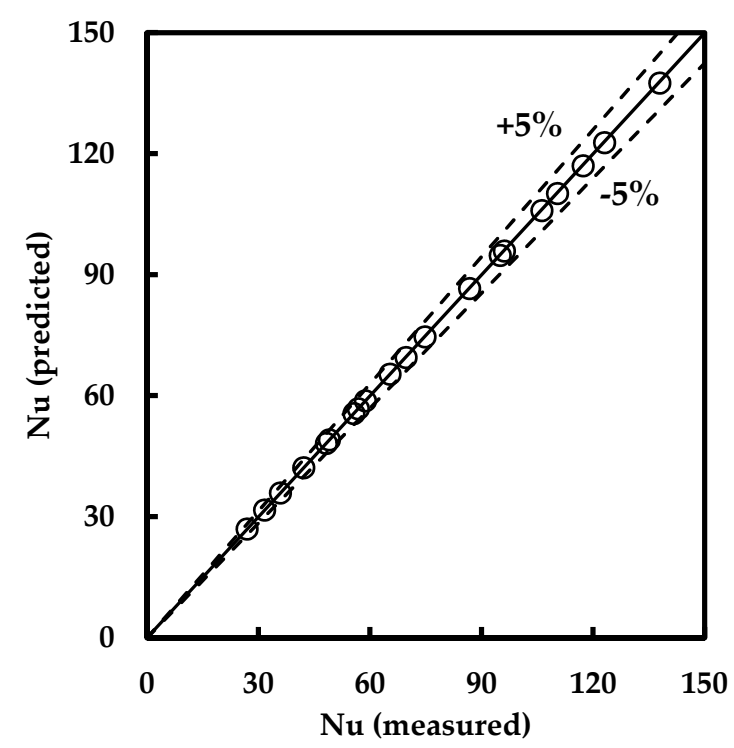

(a) Plate side

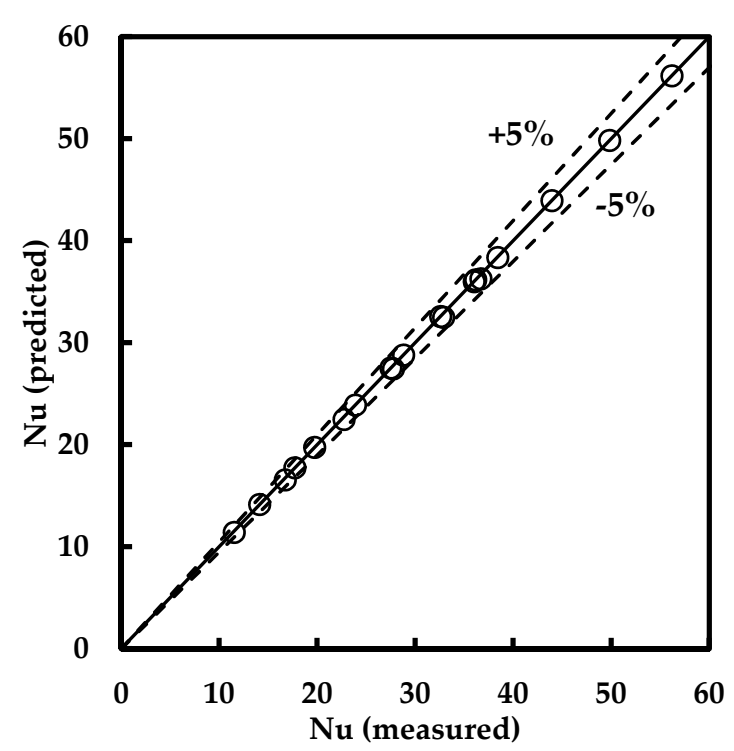

(b) Shell side

Figure 7. Predicted Nusselt number vs. measured Nusselt number for all experimental cases.

The friction factor can be calculated from the following correlation for both shell and plate sides.

$$
f=f_{0} \operatorname{Re}^{f_{1}}
$$

where the parameters $f_{0}$ and $f_{1}$ can be specified based on the following correlations as functions of the chevron angle.

Shell side:

$$
\begin{gathered}
f_{0}=1.6671(\tan \alpha)^{2}-4.2324 \tan \alpha+4.5853 \\
f_{1}=-\left(0.2289(\tan \alpha)^{2}-0.7817 \tan \alpha+0.7499\right)
\end{gathered}
$$

Plate side:

$$
\begin{gathered}
f_{0}=1.3855(\tan \alpha)^{2}-0.865 \tan \alpha-0.0167 \\
f_{1}=-\left(0.0817(\tan \alpha)^{2}-0.1754 \tan \alpha+0.1317\right)
\end{gathered}
$$


Figure 8 represents the comparison between the friction factors measured from the experimental data and those obtained from the developed correlations. It is quite clear that all the experimental data can be predicted by the developed correlations within $\pm 5 \%$ with the mean deviations for the predicted friction factors for the shell and plate sides being less than $0.7 \%$.

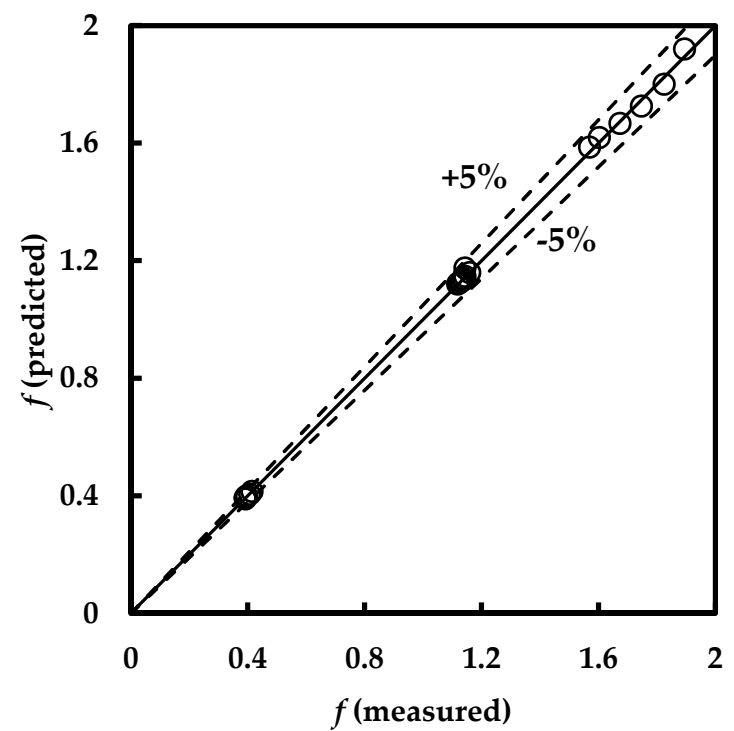

(a) plate side

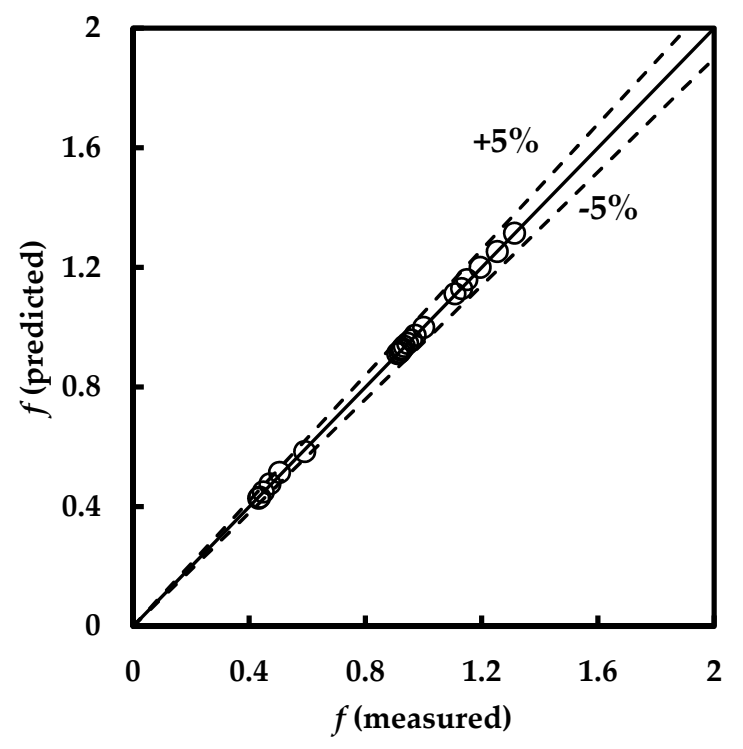

(b) shell side

Figure 8. Predicted Nusselt number vs. measured Nusselt number for all experimental cases.

It should be noted that the developed correlations were obtained in the range of $45^{\circ} \leq \alpha \leq 65^{\circ}$. More experiments are needed in the future in order to develop more generalized correlations.

\section{Conclusions}

This study conducted experiments to investigate the thermofluid characteristics of a shell-and-plate heat exchanger with different chevron angles $\left(45^{\circ} / 45^{\circ}, 45^{\circ} / 65^{\circ}\right.$, and $\left.65^{\circ} / 65^{\circ}\right)$ and a plate diameter of $440 \mathrm{~mm}$. Water was used as the working fluid on both sides and the corresponding temperatures ranged from $30-70{ }^{\circ} \mathrm{C}$. The flow rates in the plate or shell side ranged from $10-60 \mathrm{~m}^{3} / \mathrm{h}$. The heat transfer and frictional characteristics of the measurements are in terms of the Nusselt number and friction factor vs. Reynolds numbers. The heat transfer characteristics were obtained through the typical Wilson plot technique. Empirical correlations were developed for the Nusselt number and friction factor for both the shell and plate sides. Based on the above discussion, several major conclusions are drawn as follows:

- $\quad$ For all cases, the Nusselt number increases with an increase in the Reynolds number, while the friction factor decreases with an increase in the Reynolds number.

- For the heat transfer performance on the plate side, a higher chevron angle $\left(65^{\circ} / 65^{\circ}\right)$ significantly outperforms that of a low chevron angle $\left(45^{\circ} / 45^{\circ}\right)$. Additionally, the effect of the chevron angle becomes even more pronounced at high Reynolds numbers. This is because better flow distribution can be achieved.

- Unlike the plate side, an increase in the chevron angle has a negative effect on the heat transfer performance. This is because of the presence of the distribution/collection manifold on the shell side, which results in appreciable secondary flow behind the manifold and lessens the influence of the plate geometry. This opposite effect is more prominent at low Reynolds numbers due to the comparatively large contribution of the manifold. 
- The friction factor is increased appreciably with an increase in the chevron angle. However, when changing the chevron angle from $45^{\circ} / 45^{\circ}$ to $65^{\circ} / 65^{\circ}$, the increase in the friction factor is about 3-4 times on the plate side while it is about 2 times on the shell side. Again, this can be attributed to the presence of the distribution/collection manifold on the shell side.

- The developed correlations for the Nusselt number and the friction factor as functions of the Reynolds number, Prandtl number, and chevron angle can predict all the experimental data accurately with mean deviations less than $1 \%$.

Author Contributions: All authors contributed to the preparation of this research article. H.L. conducted experiments and funding acquisition. P.-L.K. analyzed data and prepared the results. The original draft of the article was prepared by A.S. Supervision of the research and review and editing of the article was performed by C.-C.W. All authors have read and agreed to the published version of the manuscript.

Funding: This research was funded by the Ministry of Science and Technology of Taiwan, grant numbers 108-2811-E-009-539 and 108-2622-E-009-027-CC2.

Acknowledgments: The authors would like to thank the Ministry of Science and Technology of Taiwan for their financial support, under contract numbers 108-2811-E-009-539 and 108-2622-E-009-027-CC2.

Conflicts of Interest: The authors declare no conflict of interest.

\section{Nomenclature}

A

$c_{p}$

$D$

$D_{h}$

$d_{p}$

$d_{s}$

$f$

$h$

$h_{w}$

$k$

$k_{p}$

l

$l_{p}$

$l_{S}$

$l_{w}$

$\dot{m}$

N

$\mathrm{Nu}$

P

Pr

$\dot{Q}$

$\operatorname{Re}$

T

$t$

U heat transfer surface area $\left(\mathrm{m}^{2}\right)$

specific heat capacity $(\mathrm{J} / \mathrm{kg} \cdot \mathrm{K})$

plate outside diameter $(\mathrm{m})$

hydraulic diameter $(\mathrm{m})$

inlet \& outlet nozzle diameters (plate side) (m)

inlet \& outlet nozzle diameters (shell side) (m)

friction factor

heat transfer coefficient $\left(\mathrm{W} / \mathrm{m}^{2} \cdot \mathrm{K}\right)$

wavy height (m)

fluid thermal conductivity $(\mathrm{W} / \mathrm{m} \cdot \mathrm{K})$

plate thermal conductivity $(\mathrm{W} / \mathrm{m} \cdot \mathrm{K})$

distance between inlet \& outlet nozzles (m)

distance between inlet \& outlet nozzles (plate side) (m)

distance between inlet \& outlet nozzles (shell side) (m)

wavy length $(\mathrm{m})$

mass flow rate $(\mathrm{kg} / \mathrm{s})$

number of plates

Nusselt number

pressure $(\mathrm{Pa})$

Prandtl number

total heat transfer rate from the hot side to cold side (W)

Reynolds number

temperature $(\mathrm{K})$

plate thickness (m)

overall heat transfer coefficient $\left(\mathrm{W} / \mathrm{m}^{2} \cdot \mathrm{K}\right)$

mean channel flow velocity in the maximum cross-sectional area of plate $(\mathrm{m} / \mathrm{s})$ 
Greek symbols

$\begin{array}{ll}\alpha & \text { average chevron angle (rad) } \\ \beta & \text { chevron angle }\left(^{\circ}\right) \\ \Delta P & \text { pressure drop }(\mathrm{Pa}) \\ \Delta T & \text { temperature difference between inlet and outlet }(\mathrm{K}) \\ \Delta T_{l m} & \text { logarithmic mean temperature difference }(\mathrm{K}) \\ \mu & \text { dynamic viscosity }(\mathrm{kg} / \mathrm{m} \cdot \mathrm{s}) \\ \rho & \text { density }\left(\mathrm{kg} / \mathrm{m}^{3}\right) \\ \varphi & \text { enlargement ratio } \\ \omega & \text { uncertainty } \\ & \\ \text { Subscripts } & \\ a & \text { acceleration } \\ f & \text { frictional } \\ g & \text { elevation } \\ \text { in } & \text { inlet } \\ \text { out } & \text { outlet } \\ p & \text { plate side } \\ \text { port } & \text { port } \\ s & \text { shell side }\end{array}$

\section{Appendix A}

The procedure of the uncertainty calculation for the overall heat transfer coefficient $(U)$ is as follows:

$$
\begin{gathered}
\dot{Q}=\dot{m} c_{p} \Delta T=U A \Delta T_{l m} \\
\omega_{\dot{Q}}=\frac{d \dot{Q}}{\dot{Q}}=\sqrt{\left(\frac{\partial \dot{Q}}{\partial \dot{m}} \omega_{\dot{m}}\right)^{2}+\left(\frac{\partial \dot{Q}}{\partial c_{p}} \omega_{c_{p}}\right)^{2}+\left(\frac{\partial \dot{Q}}{\partial \Delta T} \omega_{\Delta T}\right)^{2}} \\
\omega_{U A}=\frac{d(U A)}{U A}=\sqrt{\left(\frac{\partial(U A)}{\partial \dot{Q}} \omega_{\dot{Q}}\right)^{2}+\left(\frac{\partial(U A)}{\partial \Delta T_{l m}} \omega_{\Delta T_{l m}}\right)^{2}} \\
\omega_{U}=\frac{d U}{U}=\sqrt{\left(\frac{\partial U}{\partial(U A)} \omega_{U A}\right)^{2}+\left(\frac{\partial U}{\partial \mathrm{A}} U_{\mathrm{A}}\right)^{2}}
\end{gathered}
$$

where $\omega$ represents the uncertainty of each parameter. $c_{p}$ is dependent to the temperature and its uncertainty is calculated based on the uncertainty of the temperature measurement. The uncertainties of $\Delta T$ and $\Delta T_{l m}$ are also dependent to the temperature measurement. The uncertainty of $\dot{m}$ can be calculated based on the uncertainty of the flow rate measurement. The fabrication and dimensional measurement errors produce the uncertainty of $A$. Hence, the uncertainties from measurements can cause uncertainty in the calculation of the overall heat transfer coefficient $(U)$ based on the correlations (A1) to (A4). This procedure can be used for the calculation of the uncertainties for all parameters such as the friction factor and the heat transfer coefficient.

\section{References}

1. Goyder, H. Flow-induced vibration in heat exchangers. Chem. Eng. Res. Des. 2002, 80, 226-232. [CrossRef]

2. Uehara, H.; Kusuda, H.; Monde, M.; Nakaoka, T.; Sumitomo, H. Shell-and-plate-type heat exchangers for OTEC plants. Trans. ASME 1984, 106, 286-290. [CrossRef]

3. Nakaoka, T.; Uehara, H. Performance test of a shell-and-plate type evaporator for OTEC. Exp. Therm. Fluid Sci. 1988, 1, 283-291. [CrossRef]

4. Uehara, H.; Stuhlträger, E.; Miyara, A.; Murakami, H.; Miyazaki, K. Heat transfer and flow resistance of a shell and plate-type evaporator. Trans. ASME 1997, 119, 160-164. [CrossRef]

5. Park, J.H.; Kwon, Y.C.H.; Kim, Y.S. Experimental study on R-410A condensation heat transfer and pressure drop characteristics in oblong shell and plate heat exchanger. In Proceedings of the International Refrigeration and Air Conditioning Conference, Purdue, IN, USA, 12-15 July 2004. 
6. Park, J.-H.; Kim, I.-K.; Kim, Y.-S. Experimental study on R-410A evaporation heat transfer characteristics in shell and plate heat exchanger. J. Korean Soc. Mar. Eng. 2005, 29, 49-59.

7. Kim, I.-K.; Park, J.-H.; Kwon, Y.-H.; Kim, Y.-S. Experimental study on R-410A evaporation heat transfer characteristics in oblong shell and plate heat exchanger. Heat Transfer Eng. 2007, 28, 633-639. [CrossRef]

8. Park, J.-H.; Kim, Y.-S. Evaporation heat transfer and pressure drop characteristics of R-134a in the oblong shell and plate heat exchanger. KSME Int. J. 2004, 18, 2284-2293. [CrossRef]

9. Taylor, C.; John, R.; Williams, J.L. Shell and plate feedwater heater prototype test. In Proceedings of the ASME Power Conference, Baltimore, MD, USA, 28-31 July 2014; p. V001T03A008.

10. Arsenyeva, O.P.; Tovazhnyanskyy, L.L.; Kapustenko, P.O.; Khavin, G.L.; Yuzbashyan, A. Shell-and-plate heat exchangers for efficient heat recovery under the industrial application. Chem. Eng. Trans. 2015, 45, 1231-1236.

11. Lim, J.; Song, K.S.; Kim, D.; Lee, D.; Kim, Y. Condensation heat transfer characteristics of R245fa in a shell and plate heat exchanger for high-temperature heat pumps. Int. J. Heat Mass Transf. 2018, 127, 730-739. [CrossRef]

12. Albrecht, K.J.; Ho, C.K. Design and operating considerations for a shell-and-plate, moving packed-bed, particle-to-sCO2 heat exchanger. Sol. Energy 2019, 178, 331-340. [CrossRef]

13. Li, B.; Guo, S.; Cai, B.-H.; Wang, B. Design and fatigue analysis of high pressure shell and plate heat exchanger. IOP Conf. Ser. Earth Environ. Sci. 2019, 233, 052025. [CrossRef]

14. Abbas, A.; Lee, H.; Sengupta, A.; Wang, C.-C. Numerical investigation of thermal and hydraulic performance of shell and plate heat exchanger. Appl. Therm. Eng. 2020, 167, 114705. [CrossRef]

15. Jo, C.; Lee, D.; Chung, H.J.; Kang, Y.; Kim, Y. Comparative evaluation of the evaporation heat transfer characteristics of a low-GWP refrigerant R-1234ze (E) between shell-and-plate and plate heat exchangers. Int. J. Heat Mass Transf. 2020, 153, 119598. [CrossRef]

16. Song, K.S.; Yun, S.; Lee, D.; Kim, K.; Kim, Y. Evaporation heat transfer characteristics of R-245fa in a shell and plate heat exchanger for very-high-temperature heat pumps. Int. J. Heat Mass Transf. 2020, 151, 119408. [CrossRef]

17. Wang, K.; Wu, P.; Tang, Z.; Liu, L.; Zhao, J.; Lin, R. Flow patterns and pressure drop in the shell-and-plate heat exchangers. Int. J. Multiphas Flow 2020, 129, 103323. [CrossRef]

18. Wilson, E. A basis for rational design of heat transfer apparatus. J. Am. Soc. Mech. Engrs. 1915, 37, $546-551$.

19. Fernandez-Seara, J.; Uhía, F.J.; Sieres, J.; Campo, A. A general review of the Wilson plot method and its modifications to determine convection coefficients in heat exchange devices. Appl. Therm. Eng. 2007, 27, 2745-2757. [CrossRef]

20. Moffat, R.J. Describing the uncertainties in experimental results. Exp. Therm. Fluid Sci. 1988, 1, 3-17. [CrossRef]

21. Muley, A.; Manglik, R. Experimental study of turbulent flow heat transfer and pressure drop in a plate heat exchanger with chevron plates. Trans. ASME 1999, 121, 110-117. [CrossRef]

(C) 2020 by the authors. Licensee MDPI, Basel, Switzerland. This article is an open access article distributed under the terms and conditions of the Creative Commons Attribution (CC BY) license (http://creativecommons.org/licenses/by/4.0/). 